\title{
ENTREVISTA
}

\section{LA IMPORTANCIA DE LA PROPIEDAD EMOCIONAL EN LA EMPRESA FAMILIAR}

\author{
The importance of emotional property in family business
}

\author{
Ambroggio, Natalia E. \\ Instituto Agrotécnico "Pedro M. Fuentes Godo" \\ Av. Las Heras 727, (3500) Resistencia Chaco \\ * nataliaeambroggio@yahoo.com.ar
}

\section{Para que las empresas familiares crezcan y continúen en el tiempo será necesario que la próxima generación se ponga la camiseta con compromiso y participación.}

La presente entrevista fue realizada el 21 de abril de 2020 a la psicóloga (Doctora) Sara Rozenblum de Horowitz, formada en negociación en la estadounidense Universidad de Harvard, Asesora de Empresas Familiares y Directora del Posgrado Interdisciplinario de Negociación en Empresas del Agro de la Escuela para Graduados de FAUBA. La entrevista se basó en una investigación que realizaron Åsa Björnberg y Nigel Nicholson en el 2008 a más de 600 familiares respecto a la próxima generación en 67 países, incluida la Argentina. Los encuestados tenían entre 22 y 40 años y el grupo etario con más participantes es el de 31 a 40 años.

Solo un 30 por ciento de las empresas familiares existentes pasan a la siguiente generación, por ello, es importante que en la empresa familiar se desarrolle la propiedad emocional.

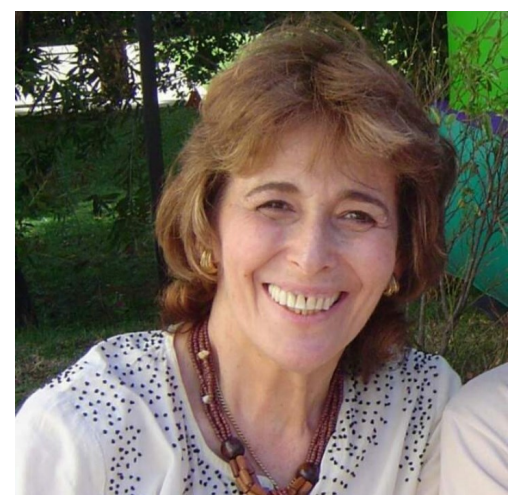

Psicóloga (Doctora) Sara Rozenblum de Horowitz, asesora de empresas familiares y directora del Posgrado Interdisciplinario en Negociación en Empresas del Agro de la Escuela para Graduados de la Facultad de Agronomía de la Universidad de Buenos Aires.

\section{¿Qué características tiene el capital en las empresas familiares?}

En la empresa familiar existen distintos tipos de capitales a saber: el capital económico - financiero, que es el que más se releva o prensa tiene y por el otro lado el capital humano, que incluye el capital intelectual (consiste en habilidad, educación y experiencia), emocional (confianza, afecto que comparten) y el espiritual (comprende valores comunes, código ético, afiliación religiosa, ritos que unen a la familia).

Recibido: 20/may/2020 


\section{¿Cómo se define a la propiedad emocional?}

La propiedad emocional es una sensación de cercanía y pertenencia que tienen los miembros de la familia, con respecto a la empresa familiar, lo que los psicólogos llaman "apego", sentido de pertenencia. Al crecer, cuando esto se afianza, formará parte de la identidad de la persona.

Tiene que ver con "ponerse la camiseta", lograr que la próxima generación tome la posta de la empresa, sintiendo que es de ellos también.

La empresa cuando se funda tiene una misión que es el objetivo comercial. La misión es el objetivo del negocio que responde a las preguntas: ¿qué vamos a hacer?, ¿para qué? y ¿cómo?. Es el objetivo y son los logros económicos que pueden ir más allá de vender la cosecha, podría llegar a ayudar y apoyar a la comunidad. Tiene también una visión que es lo que nos guía e ilumina, son los valores religiosos, la filosofía que nos sustenta, el modo de ser, lo que se puede y lo que no, nuestra relación con el medio ambiente etc.

Elegir: La visión tiende a incluir lo social y lo ecológico. Es decir, la empresa no es solo vender el grano sino que también busca alimentar, cuidar el medioambiente y transmitir a la siguiente generación.

En ese sentido, en el agro prevalece el sentimiento de que uno es el cuidador del campo para los hijos y los nietos, a lo que ahora se le agrega que uno también cuida el medioambiente para ellos.

\section{¿Cómo generar la propiedad emocional en los más jóvenes?}

La propiedad emocional en la empresa debe construirse. Las familias necesitan tomar las medidas correctas para crear y mantener la propiedad emocional. Es un proceso de toda la vida. Implica niveles más altos de compromiso de los dueños y de los líderes. Es necesario motivar y contagiar pasión por la empresa.

Cuanto más involucre activamente la empresa a un familiar, más aumentará su propiedad emocional hacia ella, y cuanta más alta esta sea, tenderá más a colaborar e involucrarse.

La propiedad emocional tiene que ver con generosidad, porque desde chicos, se abre hacia los hijos la participación. Con los hijos se comparte información, se les trasmite ideas, se los escucha, se los debe tomar como personas que pueden entender y a veces opinar.

La propiedad emocional aumenta cuando esa conexión es tangible, cuando los hijos dicen "si, soy importante para mi padre y para la empresa y ellos me consultan de verdad". Los jóvenes reciben información de la empresa, de lo que va sucediendo y además, empiezan a tener algún tipo de responsabilidad acorde a su edad.

Hay dos cosas que refuerzan la propiedad emocional en los hijos cuando son más grandes, una es que comienzan a entender que tienen o tendrán derechos como dueño y la otra es que ven, captan o perciben a la empresa como una inversión financiera, porque ponerse la camiseta tiene que ver con sentirlo propio.

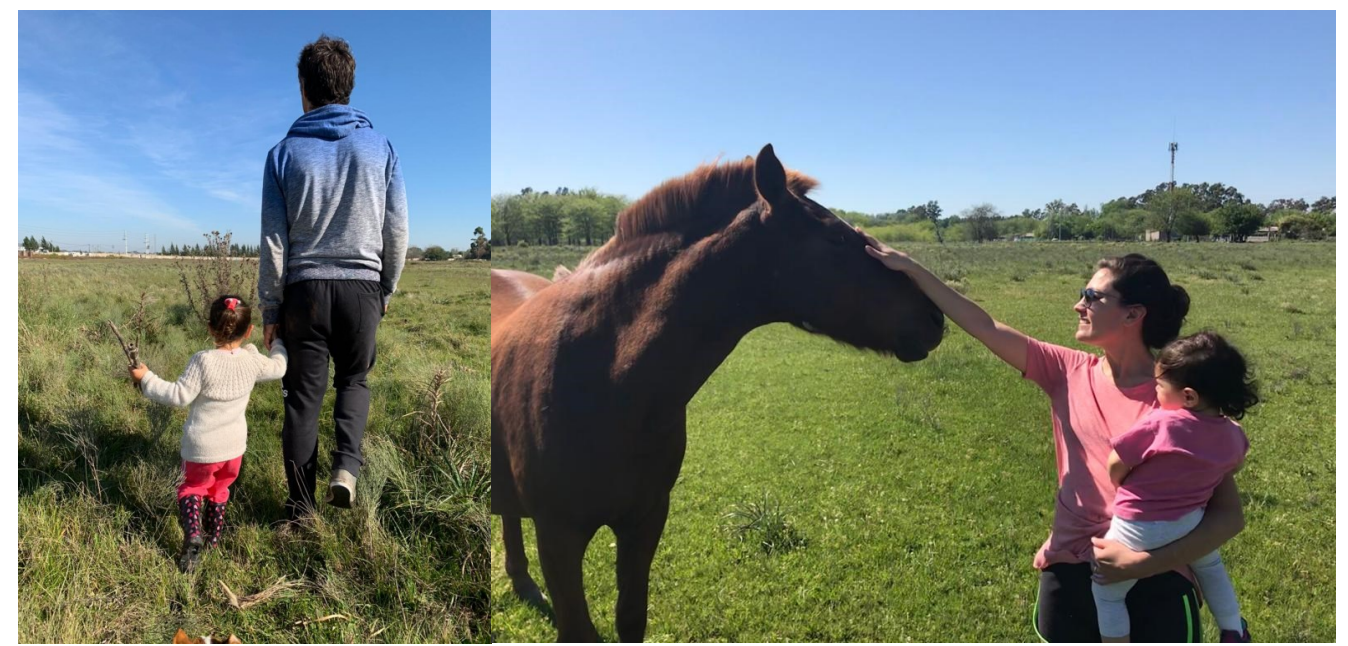

La propiedad emocional se desarrolla desde la niñez, significa confianza y afecto a lo que se comparte. Es una sensación de cercanía y pertenencia que tienen los miembros de la familia con respecto a la empresa familiar. 
Ambroggio, N.E.: La importancia de la propiedad emocional en la empresa familiar.

\section{¿A qué edad se acentúa la propiedad emocional?}

En realidad se construye entre la salida de la Universidad y los 40 años. La propiedad emocional es más fuerte en los "años de adultez temprana" es decir entre los 31 y 40 años. Estos son los años de mayor adhesión.

\section{¿Qué factores tienen que ver con la propiedad emocional?}

Pareciera que en la elección también influye el nivel de educación alcanzado. Por ejemplo, tener una maestría en administración de empresas, aumenta la propiedad emocional, porque son especialidades que se preparan para gestionar una empresa. No cualquier posgrado, los que se relacionan con gestión o temas empresariales.

\section{¿Qué pasa con el clima familiar?}

El estudio demuestra que una familia cálida emocionalmente, que es dinámica, cohesiva, flexible y amorosa, contiene a sus miembros, no los expulsa y esto hace a un buen clima familiar. Esta parece ser la mayor garantía de propiedad emocional en la próxima generación.

\section{¿Qué cosas elevan la propiedad emocional?}

Esta investigación sostiene que la pertenencia en las redes sociales eleva la propiedad emocional, por ejemplo Facebook e Instagram, mientras que las formas de comunicación menos personales, como los boletines y las páginas web estáticas, no llevan a la participación ni a ponerse la camiseta de la empresa. También dice que las personas que tienen de modo temprano más claras sus elecciones de carrera, tienen una propiedad emocional más alta.

\section{¿Cuáles son los principios que gobiernan la propiedad emocional?}

La propiedad emocional es resistente, pero no es inmune a ciertos tipos de conflicto, discriminación y formalidad excesiva. Requiere que los líderes empresariales y familiares, cultiven un clima que combine una mentalidad abierta con estabilidad.

Cuando se cambia de rumbo empresarial muy rápidamente y de forma inconsistente, parece ser más difícil ponerse la camiseta para los jóvenes. Ellos tienen que ver el potencial o atractivo a la empresa, así como futuro promisorio.

La propiedad emocional se fortalece desde la interacción social, mediante el intercambio informal de persona a persona, de corazón a corazón.

El clima familiar es esencial para la formación del desarrollo emocional, debe ser contenedor, cariñoso, dialoguista, incluyente a la hora de involucrar a la próxima generación.

\section{¿Qué consejos daría a los jóvenes de la próxima generación?}

Si quieren pertenecer a la empresa familiar, es necesario tener interés y un enfoque proactivo. Los miembros positivos y proactivos suelen obtener beneficios reales al participar en la empresa familiar, ya sea que trabajen o no en ella.

También es importante buscar información y hacer preguntas sobre la empresa. El visitar, ayudar, conocer a los empleados y cómo funciona la empresa, va creando la posibilidad de tener ganas de participar.

Otro punto importante es entender su rol o futuro rol en la empresa familiar. Poder hablar al respecto, averiguar lo que necesita saber para cumplir con su rol de socio responsable de manera efectiva.

Preguntarse siempre: ¿cómo te mantendrás actualizado acerca de lo que está pasando en la empresa y en la familia?

Generar confianza. 